\title{
Microbial antigens-loaded myeloma cells enhance Th2 cell proliferation and myeloma clonogenicity via Th2-myeloma cell interaction
}

Faqing $\operatorname{Tian}^{1 *+} \mathrm{D}$, Bo Lu ${ }^{4+}$, Ziren Chen ${ }^{5+}$, Junru Liu${ }^{2+}$, Delan $\mathrm{Ji}^{1}$, Juheng $\mathrm{Li}^{1}$, Meiqin Tang ${ }^{1}$, Wei Zhu ${ }^{3}$ and Juan $\mathrm{Li}^{2^{*}}$

\begin{abstract}
Background: Myeloma cells retain B cell functions, considered to be potential antigen presenting cells, yet there is little information regarding promoting Th2 cell proliferation or the direct effects to myeloma on the Th2 cells stimulated by microbial antigens-loaded myeloma cells.

Methods: Mixed lymphocyte reaction was used colorimetric assays via CCK8-kit. Surface molecular expression was performed by flow cytometry, cells sorting using microbeads. The concentrations of cytokines in serum were assessed using an ELISA kit. Clonogenic assay were performed in a methylcellulose culture system. Statistical analysis was assessed using the Student's t-test or one-way analysis of variance for multiple comparisons test.

Results: The expression of HLA-DR, CD80 and CD40 on RPMI8266 cell membrane surface was upregulated by interaction with interferon- $\gamma$ and/or Bacillus Calmette-Guerin Vaccine (BCGV). RPMI8266 cells were able to induce the mixed lymphocyte reaction in a dose-dependent fashion. The Th2 ratio induced by RPMI8266 treated by BCGV and interferon- $\gamma$ (treated-RPMI8266) cells was only slightly greater than by untreated-tumor cells, but the serum IL-4 level secreted by Th2 cells was markedly higher in treated-RPMI8266 cells group. Th2 cells stimulated by treatedmyeloma cells could directly promote treated-myeloma cell clonogenicity in a dose-dependent manner. AntiHLADR IgG2b completely blocked increased of IL-4 secretion by Th2 cells stimulated by treated-myeloma cells, while also blocked enhancing the clonogenicity of treated tumor cells stimulated by MM-Th2 cells.

Conclusions: These results indicate that a novel mechanism of myeloma pathogenesis in myeloma cells could act as an APC to present microbial Ags to Th2 cells, promoting Th2 cell proliferation, consequently facilitating tumor development by close interaction between Th2 myeloma cells. Taken together, the microbial Ag presenting course of MM-Th2-MM interactions_-restricted by MHC class-I-may result in tumor development such that all factors involved in the system could have a potential for myeloma therapeutic intervention.
\end{abstract}

Keywords: Myeloma, Microbial antigen, Antigen presenting cells, Th2 cell, Clonogenicity, MHC- II restriction

\footnotetext{
*Correspondence: trumantfa@163.com; lijuan_happy@163.com

${ }^{\dagger}$ Faqing Tian, Bo Lu, Ziren Chen and Junru Liu contributed equally to this work.

${ }^{1}$ Department of Hematology, Longgang District People's Hospital of Shenzhen, Shenzhen 518172, Guangdong, China

${ }^{2}$ Department of Hematology, The First Affiliated Hospital, Sun Yat-Sen

University, Guangzhou 510080, Guangdong, China

Full list of author information is available at the end of the article
}

(c) The Author(s). 2019 Open Access This article is distributed under the terms of the Creative Commons Attribution 4.0 International License (http://creativecommons.org/licenses/by/4.0/) which permits unrestricted use, distribution, and reproduction in any medium, provided you give appropriate credit to the original author(s) and the source, provide a link to the Creative Commons license, and indicate if changes were made. The Creative Commons Public Domain Dedication waiver (http://creativecommons.org/publicdomain/zero/1.0/) applies to the data made available in this article, unless otherwise stated. 


\section{Background}

Multiple myeloma (MM) is a B cell tumor that is characterized by the clonal expansion of malignant plasma cells in bone marrow [1]. A typical feature of MM is that it is clonally committed to the production and secretion of a specific immunoglobulin. Despite progress in therapeutic treatments for the disease, MM remains an incurable malignancy $[2,3]$. Interactions involving stromal cells, as well as B- and plasma cell differentiation and growth factors-such as IL-6, BAFF and RANK-have been implicated in the development of MM [4-7]. Prior studies have demonstrated that heavy infiltration of human tumors by Dendritic cells (DCs), or polarization of Th2 cells in peripheral blood, is often correlated with an adverse prognosis [8-16]. DCs are able to directly enhance the clonogenicity of human MM by tumor-DC interactions [6]. Several studies have reported that Th2 cells have been confirmed to promote MM growth though myeloma cell-Th2 cell interactions [11, 17, 18]. Thus, antigenpresenting cells (APCs), for example DCs, and Th2 cells might play an important key in MM development.

Microbial antigens (Ags) have been demonstrated to be a potential cause of some tumors, and carcinogenesis may result from direct or indirect interaction between inflammatory cells/mediators with epithelial cells, stomal cells and extracellular matrix components, subsequently stimulating tumor angiogenesis [19-23]. Prior studies have confirmed that microbial Ags-such as Bacillus Calmette-Guerin Vaccine (BCGV) and tetanus toxoid antigen (TTA) - can enhance myeloma clonogenicity and are not just based on the level of humoral immunity [24-27]. Prior studies have also indicated that microbial Ags presented by DCs to Th2 cells (microbial Ags-Th2 cells) participate in MM pathogenesis after microbial Ags presentation by myeloma cells and DCs [17]. Therefore, the microbial Ags-Th2 cell transition is an important step in pathogenicity recurrence and MM development. Due to microbial antigens that are involved in many immune responses with affect a variety of immune cell functions, microbial Ags were posited to deeply affect myeloma biology from different aspects, possibly contributing to tumor cell growth.

Myeloma plasma cells, as APCs, can activate the immune response $[17,25]$. These cells express a variety of surface markers, such as MHC-I, and surface antigens that are necessary for professional APCs, including adhesion and costimulation, but there are little expression of MHC-II, CD40 and CD80. Some studies have proven that MHC-II, CD40 and CD80 could be upregulated by interferon- $\gamma$ (IFN- $\gamma$ ), tumor necrosis factor- $\alpha$ and microbial Ags, which is essential for APCs to activate Th2 cells $[17,24]$. Myeloma cells are able to stimulate T cells and present the soluble antigens to autologous $\mathrm{T}$ cells, which are mainly Th1 cells that secrete IFN- $\gamma[11,25]$.
The ability of myeloma cells to stimulate and upregulate Th2 remains to be elucidated, similar to myelomastimilating-Th2 cells (MM-Th2) that act on myeloma cells to enhance clonogenicity. Th2 cells are polarized in MM patients and can induce MM cell proliferation [11, 17, 28, 29]. Therefore, the ability of myeloma cells to present microbial Ags to Th2 cells, and the role of these Th2 cells in promoting myeloma growth at same time, requires further investigation.

\section{Methods \\ Healthy donor samples, patient samples and human myeloma cell lines}

Peripheral blood and bone marrow aspirates were collected from healthy donors and four patients with MM. The RPMI8226 cell line was from the American Type Culture Collection (ATCC, Manassas, VA, USA) in 2015, and no further authentications were performed by the authors, not tested for mycoplasm contamination also.

\section{Mixed lymphocyte reaction (MLR)}

We used the RPMI8226 multiple myeloma (MM) cell line as a model system to investigate whether MM cells are capable of presenting microbial antigens to $\mathrm{T}$ cells via MHC II, and whether that affects the response to $\mathrm{T}$ cells to MM cells in a mixed lymphocyte reaction (specific methods in a Additional file).

\section{Flow cytometry analysis}

RPMI8266 cells were treated with IFN- $\gamma$ and/or BCGV for $48 \mathrm{~h}$. The myeloma cells were then stained with several defined antibodies and forward scatter flow cytometry (FCM) was used to measure the change in surface expression of CD80, CD86, CD40, CD54, and HLA-DR. After coculture with treated-MM cells for 5 days (MM: $\mathrm{T}=1: 1), \mathrm{CD}^{+} \mathrm{CyIL}-4^{+} \mathrm{Th} 2$ cells were analyzed by flow cytometry (FCM). Data were collected and analyzed using a FACScalibur flow cytometer and Cell Quest software (BD Biosciences, San Jose, CA, USA).

\section{ELISA assay}

The concentrations of IL-4, IL-12 and IFN- $\gamma$ in serum were assessed using an ELISA kit (R\&D Systems, Minneapolis, MN, USA) according to the manufacturer's instructions.

\section{Isolation of MM-Th2 cells}

BCGV-loaded MM cells (treated-MM cells) were added to the $\mathrm{T}$ cells at a ratio of 1:1 in the presence of IL-2 (10 ng/ml; PeproTech, Rocky Hill, NJ, USA). After 5-7 days, MM-Th2 cells were isolated using $\mathrm{CD}^{+}$and CD294 ${ }^{+}$(CRTH2) microbeads (Miltenyi Biotec, GmbH, Bergisch Gladbach, Germany) from the MM cell-T-cell 
coculture system according to the manufacturer's instructions [30].

\section{Clonogenic assays of RPMI8266 cells cocultured with Th2 cells}

MM-Th2 cells (purity > 95\%) irradiated with 30 Gy from a ${ }^{137} \mathrm{Cs}$ source were added to treated-RPMI8266 cells at a ratio of $0: 1,1: 1,10: 1,20: 1,40: 1$ (tumor cells: 10,000/ well), mixed completely and cocultured for $12 \mathrm{~h}$ for clonogenic assays. The clonogenic growth was evaluated by plating tumor cells in quadruplicate $35-\mathrm{mm}^{2}$ tissue culture dishes, and for specific experimental methods, please refer to reference 17. Tumor colonies were counted after 2-3 weeks of culturing. The phenotype of the cells was confirmed by flow cytometry.

\section{Clonogenic assay of primary tumor cells}

Mononuclear cells were isolated from the bone marrow samples of four MM patients using density gradient centrifugation, followed by treatment with IFN- $\gamma$ and BCGV for $24 \mathrm{~h}$. Then $\mathrm{CD} 138^{+}$and $\mathrm{CD} 138^{-}$fractions were isolated and plated with or without MM-Th2 cells at a ratio of 1:20 (MM:T) in a methylcellulose culture system as described in reference 17.

\section{MHC- II restriction}

In order to study the role of MHC molecules in Th2 cell and treated-MM cell interactions, cells were incubated with mouse MoAb against HLA-DR (IgG2b; $1 \mu \mathrm{g} / \mathrm{mL}$; Millipore, Billerica, MA, USA), mouse MoAb against MHC--I (IgG2b; $5 \mu \mathrm{g} / \mathrm{mL} ; \mathrm{R} \& D$ Systems, Minneapolis, $\mathrm{MN}$, USA), or control IgG2b $(5 \mu \mathrm{g} / \mathrm{mL})$ In order to assess the myeloma cell- $T$ cell contact dependence of tumor cell clonogenicity, Transwell polyester membrane inserts (CLS3460, Corning, Inc., Corning, NY, USA) separating treated-RPMI8266 cells from MM-Th2 cells were compared with control inserts separating MM-Th2 cells from complete RPMI-1640 medium only.

\section{Statistical analysis}

Differences between groups were assessed using the Student's t-test or one-way analysis of variance for multiple comparisons test. The significance level was set at $P<0.05$.

\section{Results}

\section{Change in expression of surface markers on RPMI8266 cells}

The expression of some markers (HLA-DR, CD40, CD80, CD86 and CD54) indicated that MM cells and Th2 cells are able to activate one another. On RPMI8266 cells, HLA-DR, CD40 and CD80 were expressed at a low level, while CD86 and CD54 were highly expressed. Treatment with IFN- $\gamma$ for $48 \mathrm{~h}$ markedly increased the surface expression of HLA-DR, CD40 and CD80 (Additional file 1: Figure S1a) and BCGV alone upregulated HLA-DR, CD40 and CD80 expression (Additional file 1: Figure S1b). Therefore, IFN- $\gamma$ and/ or exogenous Ag were able to directly alter the expression of surface molecules on RPMI8266 cells, suggesting that MM cells may act as APC in a similar manner to B cells.

\section{MLR of RPMI8266 cells}

In order to assess the presentation of antigen to $\mathrm{T}$ cells by RPMI8266 cells, MLR was performed after RPMI8266 cells were treated with IFN- $\gamma$ and BCGV for $48 \mathrm{~h}$ (treated-RPMI8266 cells). Treated-RPMI8266 cells induced proliferation of $\mathrm{T}$ cells in a dose-dependent manner. Treated-RPMI8266 cells had enhanced MLR than untreated RPMI8266 and T cells, and were similar to monocyte cells (Mo Cells) (Fig. 1a). FCM indicated that Th2 cell ratio produced by treated-RPMI8266 cells in PBMC was slightly higher than by untreated-RPMI8266 cells and by PBMC alone (Fig. 1b, Additional file 1: Figure S2).

\section{Cytokines levels}

IL-4, IFN- $\gamma$, and IL-12 are mainly secreted by Th2 cells, Th1 cells, and $\mathrm{CD}^{+} \mathrm{T}$ (CTL) cells, respectively, while Th2 cells cannot secrete IL-12 and IFN- $\gamma$, Th1 cells cannot secrete IL-12 and IL-4, and CTL cells cannot secrete IL-4 and IFN- $\gamma$. In order to further assess T cell proliferation, changes in MLR, IL-4, IL-12 and IFN- $\gamma$ levels were determined by ELISA assay. IL-4 and IFN- $\gamma$ levels were greatly increased in the treated-RPMI8266 cells group in a dose-dependent manner, while similar increases were not observed in other groups, except for the treated-RPMI8266 cells+anti-MHC-I and the treated-RPMI8266 cells+control IgG2b groups (Fig. 2a, c). IL-12 levels increased in all groups in a dosedependent manner-except the treated-RPMI8266 cells+anti-MHC-I groups. IL-12 level was higher in untreated-RPMI8266 group than in the treatedRPMI8266 cells+anti-MHC-I group (Fig. 2b). These experiments demonstrated that myeloma cells promote the secretion of IFN- $\gamma$, IL-4 and IL-12 by activating Th1, Th2 and CTL cells, respectively. Since APC-presenting antigens promote the proliferation of CTL cells with MHC-I molecular restriction and the proliferation of Th1 and Th2 cells with MHC-II molecules. Therefore, anti-MHC-I can inhibit APCs from promoting CTL cell proliferation, and anti-MHC-II (anti-HLA-DR) can inhibit APCs from promoting Th1 and Th2 cell proliferation., which is characterized by decreased secretion of IFN- $\gamma$, L-12 and Il-4, respectively. Therefore, this experiment indirectly proves that myeloma cell is a kind of APC to produce mixed lymphocyte reaction, which can present BCG antigen to $\mathrm{T}$ cells, simultaneously greatly 

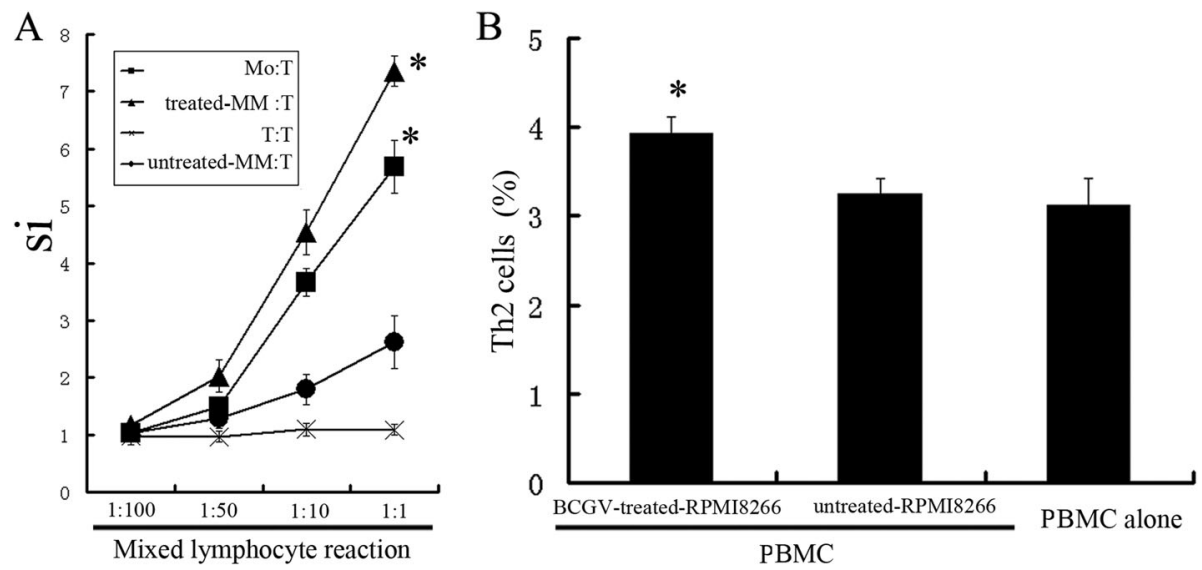

Fig. 1 Mixed lymphocyte reaction and Th2 cell ratio. Colorimetric assays were performed to evaluate the MLR. SI (the stimulus index) = A experimental well $/ A_{\text {control well. }}$ (A) Treated-RPMI8266 cells (treated with IFN- $\gamma$ and BCGV) induced proliferation of T cells in a dose-dependent manner, and treated-RPMI8266 cells had enhanced MLR in comparison to untreated RPMI8266 and T cells; ${ }^{*} p<0.05$. (B,C) Th2 cells after MLR for 5 d (MM: $\mathrm{T}=1: 1$ ) stained with CD4-FITC and IL-4-PE was analyzed by FCM. Bars represent the mean \pm SEM (error bars) of four separate experiments. The ratio of Th2 cell was weakly increased, but the total number of T cell was significantly increased many times by treated-myeloma cells after MLR, so the absolute number of Th2 cell produced by treated-myeloma was more significantly increased. Th2 cell number calculation formula: Absolute number $_{T h 2}=$ Total number $_{T \text { cell }} \times$ Ratio $_{T h 2}$

promoting the proliferation of Th1, CTL and Th2 cells and secretion of their corresponding cytokines, which restricted by $\mathrm{MHC}$ molecules.

\section{Stimulation of clonogenic growth of myeloma cells by Th2 cells}

In order to assess the response of RPMI8266 cells to Th2 cells, colorimetric assays were performed and suggested that MM-Th2 cells significantly increased the clonogenicity of treated-RPMI8266 cells in a Th2 cell: tumor cell ratio-dependent manner (Figs. 3a-d, f). In contrast, MM-Th2 cells had no impact on the clonogenicity of untreated-RPMI8266 and RPMI8266 cells treated with IFN- $\gamma$ alone (Figs. 3 e-f, h), while non-MMTh2 cells and MM-specific CTL cells $\left(\mathrm{CD} 4^{+} \mathrm{CD}^{+} \mathrm{T}\right.$ cells) had no impact on treated-RPMI8266 cells (Fig. 3c). MM-Th2 cell-mediated enhancement of tumor clonogenicity required close contact between tumor cells and Th2 cells, as the effect was not evident when the two cell populations were separated by a Transwell membrane (Fig. 3d). Therefore, interactions between treated-MM and MM-Th2 cells can directly promote MM clonogenicity. MM-Th2 cells were also able to increase the clonogenicity of primary myeloma cells treated by IFN- $\gamma$ and BCGV (Figs. 3g).

\section{The effect of blocking MHC between Th2 cells and RPMI8266 cells}

Prior studies have confirmed that myeloma cells can present Ag peptides to $\mathrm{T}$ cells, which are MHC restricted, and myeloma colony growth that is promoted by Th2 cells is mainly restricted to MHC class-II. In order to gain insight into the role of MHC-II in the interaction between MM-Th2 cells and treatedRPMI8266 cells, MoAbs against MHC-II (anti-HLA-DR MoAb) were used to inhibit Th2 cell proliferation induced by treated-RPMI8266 cells, as well as the enhancement of MM-Th2 cell-stimulated clonogenicity of treated-RPMI8266 cells. IL-12 levels were decreased by MoAbs against MHC-I, suggesting that $\mathrm{CD}^{+} \mathrm{T}$ cell proliferation induced by treated-RPMI8266 cells could be inhibited by MoAbs against MHC-I (Figs. 2b). Furthermore, pretreatment with an anti-HLA-DR MoAb could abolish the enhancement in tumor clonogenicity caused by MM-Th2 cells (Figs. 3, 3, 4b g). Therefore, cell proliferation induced by Th2 cell-myeloma cell interactions was primarily restricted to $\mathrm{MHC}$ class-II.

\section{Discussion}

Several studies have suggested that a proportion of malignant plasma cells retain B cell functions, may possess stem cell characteristics, and must interact with Th2 cells to form colonies [11, 17, 25]. In our assays, although Th2 cell ratio promoted by treated-myeloma cells was only slightly higher by FCM, the total number of $\mathrm{T}$ cell was significantly increased many times by treated-myeloma cells after MLR, so the absolute number of Th2 cell promoted by treated-myeloma was more significantly increased. Th2 cell absolute number calculation formula: Absolute number ${ }_{\text {Th2 }}=$ Total number $_{T}$ cell $\times$ Ratio ${ }_{\text {Th2 }}$. IL-4 is secreted only by Th2 cells, and its level secreted was markedly higher in treated-RPMI8266 cells group, also suggesting that proliferation of Th2 cells was greatly promoted by treated-RPMI8266 cells. 


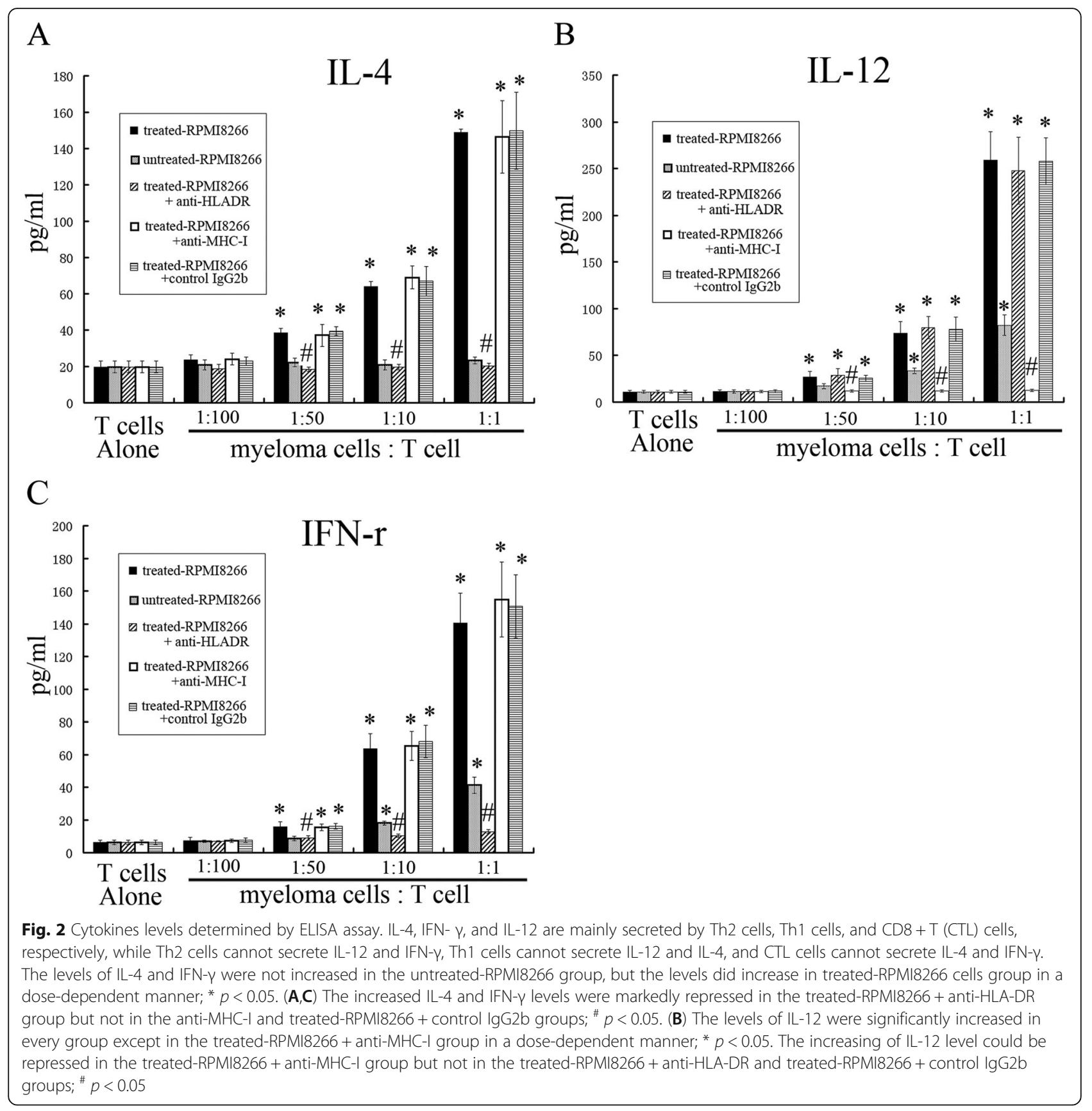

Therefore, malignant plasma cells could induce MLR, promoting $\mathrm{CD}^{+} \mathrm{T}(\mathrm{CTL})$ and $\mathrm{Th} 1$ cell proliferation and could also promote Th2 cell proliferation, suggesting that myeloma cells present Ags to T cells, including Th2 cells. In short, myeloma cells may be regarded as APC, similar to $\mathrm{B}$ cell $\mathrm{s}$, which is consistent with previous reports $[11,17,25]$. However, the MLR of untreated-MM cells was greatly reduced in comparison to treated-MM, and untreated-MM cells did not increase IL-4 levels secreted by Th2 cells, but it did in treated-MM cells. This may suggest that myeloma cells did not directly promote
Th2 cell proliferation or induce naïve $\mathrm{T}$ cells to Th2 cells until myeloma cells were treated with IFN- $\gamma$ and BCGV. Prior studies have confirmed that U266 and primary myeloma cells express B cell membrane markers, including high levels of CD86 and CD54 and detectable levels of HLA-DR, CD40 and CD80, which can be upregulated by IFN- $\gamma$ combined with microbial Ags or by BCGV alone $[17,25]$. In these assays, the expression of HLA-DR, CD40 and CD80 of RPMI8266 cells was also increased by IFN- $\gamma$ and BCGV or by BCGV alone, which is essential for APCs to activate Th2 cells, so, the 
A

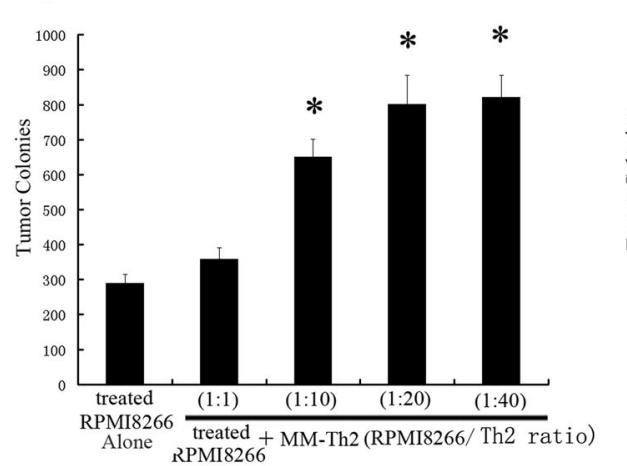

C

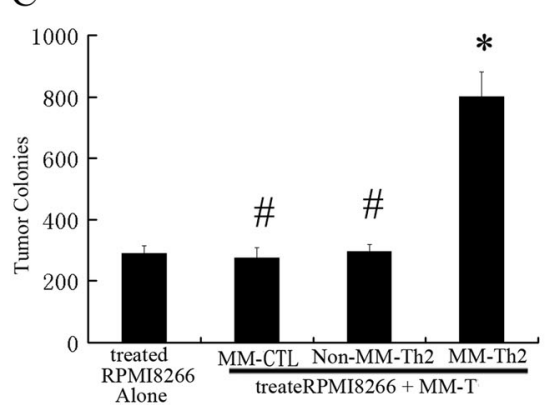

D
B
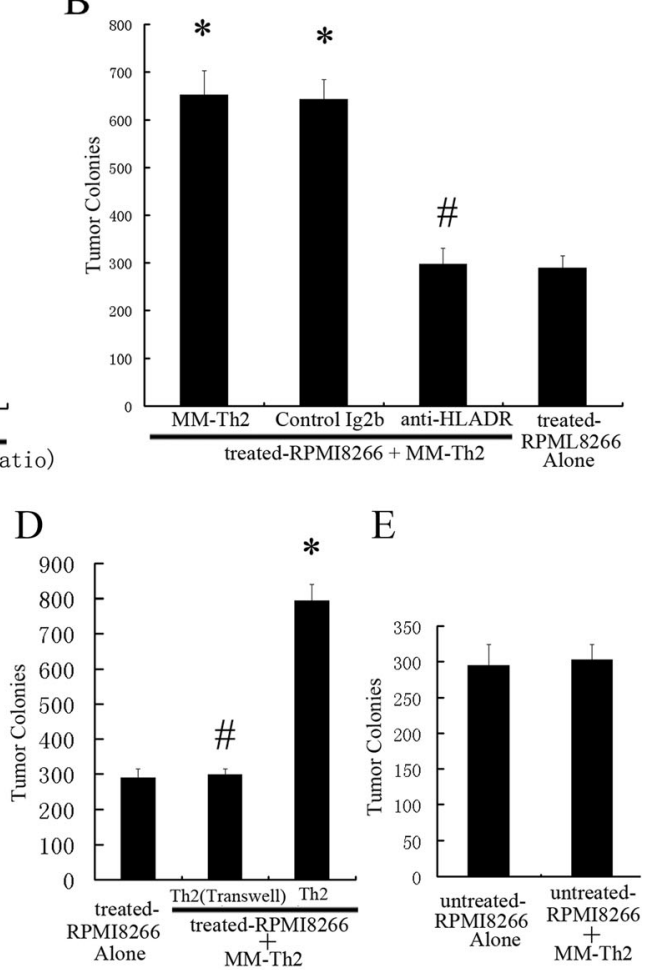

E

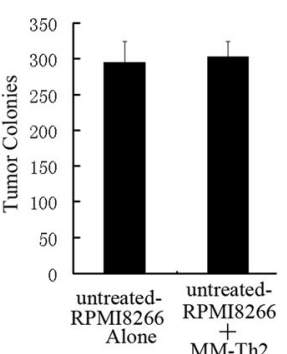

F

G
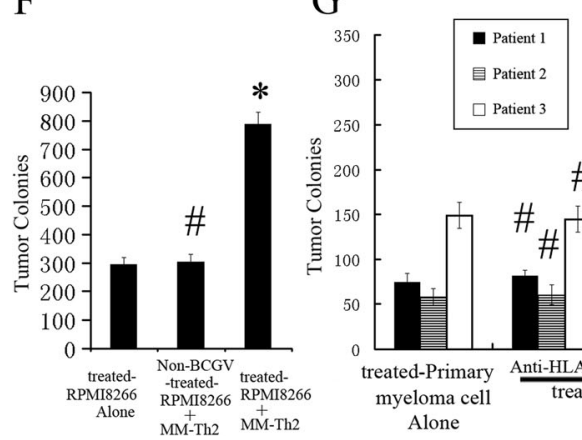

$\mathrm{H}$
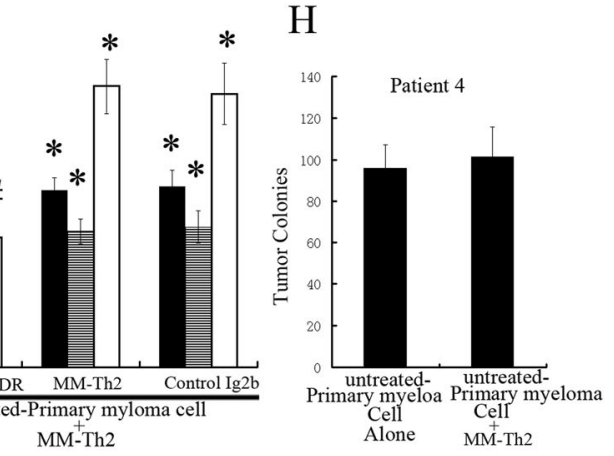

Fig. 3 Human myeloma cell clonogenicity. Colonies were counted by microscope after 2-3 weeks of culturing. IFN- $\gamma$ and BCGV-treated RPMI8266 cells were plated with or without MM-Th2 cells in a clonogenic assay (tumor cells: 10,000/well). Results are the mean \pm SEM. (error bars) of three separate experiments; ${ }^{*} p<0.05$. (A) MM-Th2 cells significantly increased the clonogenicity of treated-RPMI8266 cells in a Th2: tumor cell ratiodependent manner; * $p<0.05$. (B,C,D,F) MM-Th2 cells groups versus non-MM-Th2 cells groups (Th2/tumor ratio of 20:1). Clonogenicity was significantly enhanced by MM-Th2; ${ }^{*} p<0.05$, but reduced by anti-HLA-DR and Transwell; ${ }^{*} p<0.05$. (C) Clonogenicity of treated-RPMI8266 cells were not affected by MM-CTL cells and non-MM-Th2 cells compared with by MM-Th2; ${ }^{*} p<0.05$. (D) Requirements for cell-cell contact. MM-Th2 cells were either plated along with treated-tumor cells or separated from treated-tumor cells by a transwell insert membrane. (E,F) Untreatedtumor cells and tumor cells treated only with IFN- $\gamma$ (Non-BCGV-treated-PRMI8266) were not affected by MM-Th2 cells compared with treatedRPMI 8266; ${ }^{\prime} p<0.05$. (G,H) Clonogenicity of primary myeloma cells $(n=4)$. Tumor cells treated with IFN- $\gamma$ and BCGV (treated-primary myeloma cells) were cultured in the presence or absence of allogeneic Th2 cells (MM-Th2) at a ratio of 1:20 (tumor: Th2 cells, tumor cells: 100,000/well) in the clonogenic assay. MM-Th2 cells significantly increased the clonogenicity of treated-primary myeloma cells; $p<0.05$, but this effect was reduced by anti-HLA-DR; ${ }^{\#} p<0.05$. Untreated-primary myeloma cells were not affected by MM-Th2 cells. $(b, g)$ Control lgG2b did not repress the enhancement of clonogenicity produced by MM-Th2 cells

treated-RPMI8266 like B cells could cause Th2 cell proliferation.

Th2 cells are polarized in patients with MM and can cause MM cell proliferation or clonogenicity [11, 17, 28, 29]. DCs present microbial Ags to Th2 cells, which then directly promotes myeloma clonogenicity when myeloma encounter the same Ags by Th2 cell-myeloma cell direct interaction [16]. In these assays, myeloma cells acted as an APC that directly presents microbial Ags to promote Th2 cell proliferation (MM-Th2 cells), which in turn directly promoted 


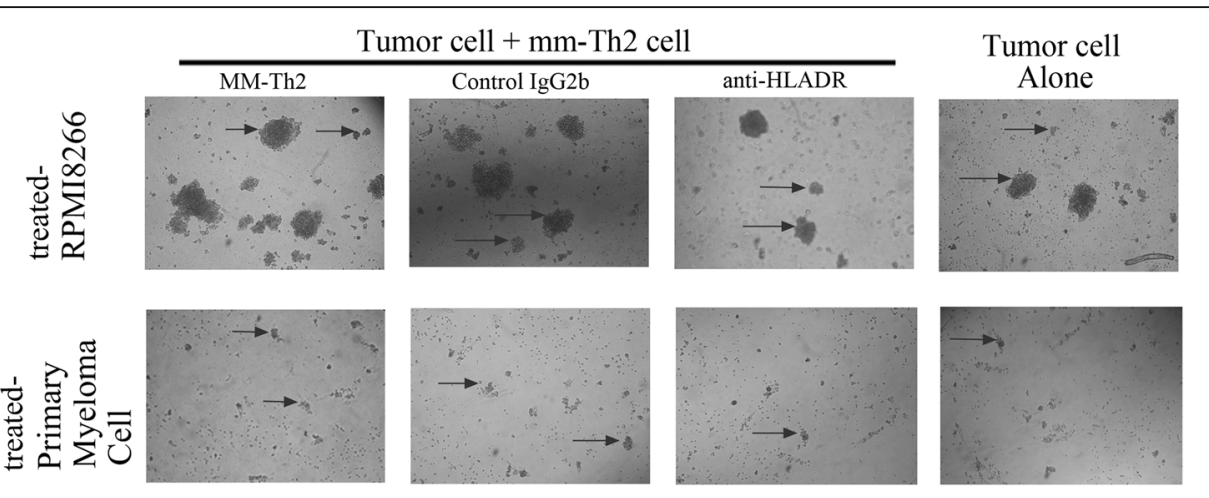

Fig. 4 Tumor colony appearance. The clonogenicity assays were performed in methylcellulose. Treated tumor cells were plated with MM-Th2 cells (Tumor + Th2), without MM-Th2 cells (tumor Alone), with MM-Th2 cells and anti-HLA-DR (Anti-HLA-DR), or with MM-Th2 cells and control $\lg$ G2b (control lgG2b). Micrographs represent the appearance of colonies at low power. (Upper panel) Appearance of colonies of treatedRPMI8266 cells (tumor cells: 10,000/well). (Lower panel) Appearance of colonies of primary myeloma cells from bone marrow (tumor cells: 100,000/well). Arrow: pointing to tumor colony

myeloma clonogenicity. In MM, DCs present microbial Ags to Th2 cells which are involved in pathogenecity, recurrence and development of MM, while myeloma cells can present microbial Ags to Th2 cells, subsequently stimulating tumor clonogenicity. However, these results do not exclude other mechanisms for $\mathrm{MM}$ pathogenesis. Blocking T-cell receptor-MHC-II interaction by anti-MHC-II MoAb (antiHLADR) completely repressed Th2 cell IL-4 secretion that was promoted by treated-myeloma cells. This decreases the amount of tumor clonogenicity stimulated by MM-Th2 cells, indicating that MHC-II restriction could be mediated by Th2 cell and treated-MM cell interactions. This data is similar to previous assays, which detailed that the interaction between Th2-myloma cells is similar to interaction between Th2 cell and B cell. These interactions require $\mathrm{T}$-cell receptor-MHC-II and CD40-CD40L binding, as well as other molecule interaction such as adhesion molecules (CD54-CD11a interaction), costimulatory molecules (B7CD28 interaction) or Toll-like receptors [17, 31-33]. The transwell assays further confirmed that the stimulation of clonogenic growth of myeloma cells by Th2 cells required close contact between tumor cells and Th2 cells, as this effect was not evident when the two cell populations were separated by a Transwell membrane. Therefore, Th2 and MM cells require close contact just like Th2 cell and B cell interactions, which are MHC class-II restricted.

Similar to previous assays [17], microbial Ags were confirmed to play an important role in the development of myeloma, but antigens presented by primary MM cells are likely to be different from what is being presented after BCGV treatment. BCGV treatment is likely to be not only a source of peptide antigen, but to stimulate MM cells through TLRs in vivo and vitro. In our assays, microbial Ags not only directly increased the expression of MHC-II, CD40 and CD80 and changing tumor biology, but the direct presentation of microbial
Ags by myeloma cells to Th2 cells could directly stimulate myeloma clonogenicity, much different from the conclusions in prior studies [19-21]. To our knowledge, this is the first observation that microbial Ags could directly affect myeloma cells to promote tumor development, as myeloma cells could present the Ags to Th2 cells. During this course, microbial Ags to promote the expression of MHC-II, CD40 and CD80 in myeloma cells may be the most critical step to stimulate tumor clonogenicity. In short, microbial antigens-loaded myeloma cells could enhance Th2 cell proliferation and myeloma clonogenicity via Th2-myeloma cell interaction.

\section{Conclusions}

In conclusion, this study presents evidence for a novel mechanism of MM pathogenesis, whereby myeloma cells act as APS to present microbial Ags to Th2 cells, in turn facilitating tumor development by Th2 cells-myeloma cells via close interactions. Thus, the microbial Ag presenting course of MM-Th2-MM interactions-restricted by MHC class-II-may result in tumor development such that every factor involved in the system may be potential targets for new myeloma therapies and interventions.

\section{Supplementary information}

Supplementary information accompanies this paper at https://doi.org/10. 1186/s12885-019-6469-4.

Additional file 1: Mixed lymphocyte reaction (MLR). Peripheral blood monocytes (PBMC) were isolated from freshly-collected heparin-treated blood by density gradient centrifugation. Subsequently, $5 \times 10^{6}$ cells $/ \mathrm{mL}$ were cultured for $2-4 \mathrm{~h}$ to permit cell adherence and the adherent cells acted as monocytes. Nonadherent cells were further depleted of normal B cells using CD19 micro beads (Miltenyi Biotec), which acted as T cells. T cells in the monocyte-depleted and B-cell-depleted population were > $95 \%$. CD $14^{+}$monocytes in adherent cells were $>60 \%$. RPMI8266 cells treated with IFN- $\gamma$ (Shanghai Prime Gene Bio-Tech Co., Shanghai, China) and BCGV for $48 \mathrm{~h}$ (treated-RPMI8266) were irradiated with $30 \mathrm{~Gy}$ from a 
${ }^{137} \mathrm{Cs}$ source and added in a gradient as stimulators to a 96-well roundbottomed microtitre plate, each well containing $200 \mu \mathrm{L}$ of $1 \times 10^{5}$ allogenic $T$ cells (experimental well). The well of allogenic $T$ cells alone was as control. Colorimetric assays were performed in order to evaluate the proliferation of T cells by treated-MM cells on day 5. Next, $20 \mu \mathrm{L}$ of CCK-8 (Cell Counting Kit-8; Dojindo, Kumamoto, Japan) were added to each well, followed by incubation at $37^{\circ} \mathrm{C}$ for $3-4 \mathrm{~h}$ in a humidified $\mathrm{CO}_{2}$ incubator for quantitative analysis of cell viability. The absorbance (A) at 450 $\mathrm{nm}$ wavelength ( $630 \mathrm{~nm}$ as control of $450 \mathrm{~nm}$ ) was monitored with a microplate reader (ELX800, BIO-TEK, USA), then to calculate the stimulus index (SI). $S I=A_{\text {experimental well }} A_{\text {control well. }}$ Figure $S 1$. Surface Ags on RPMI8266 cells treated by IFN- $\gamma$ or BCGV. Surface HLA-DR, CD40, CD80, CD86 and CD54 expression on tumor cells were examined by flow cytometry. (a) Treatment of RPMI8266 cells with IFN- $\gamma$ for $48 \mathrm{~h}$ markedly increased HLA-DR, CD40 and CD80 expression, but CD40 and CD80 expressions were at a low level. RPMI8266 cells expressed high levels of CD86 and CD54. (b) Expression of HLA-DR, CD40 and CD80 was increased after treatment of RPMI8266 cells with BCGV; ${ }^{*} p<0.05$.Figure S2. Mixed lymphocyte reaction and Th2 cell ratio. Th2 cells after MLR for $5 \mathrm{~d}$ (MM: $T=1: 1)$ stained with CD4-FITC and IL-4-PE was analyzed by FCM. The ratio of Th2 cell was weakly increased

\section{Abbreviations}

APC: Antigen-presenting cell; antigen: Ag; BCGV: Bacillus Calmette-Guerin Vaccine; CCK8: Cell Counting Kit-8; DC: Dendritic cells; FCM: Flow cytometry

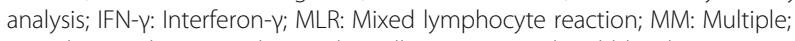
MM-Th2: Myeloma-stimilating-Th2 cells; PBMC: Peripheral blood monocyte; SI: Stimulus index; TTA: Tetanus toxoid antigen

\section{Acknowledgements}

We thank Ruixian Li, Jiali Long, and Jing Zhang for preparing bone marrow, blood sample and administrative support of this work.

\section{Authors' contributions}

$F T, J L 3, J L 1$ designed research, performed research and analyzed data. $B L$, $Z C, W Z, M T, J L 2$ and D J performed research. F T and W Z wrote the paper. All authors have read and approved the manuscript, and ensure that this is the case.

\section{Funding}

This work was supported by a grant from the Science and Technology R \& D Fund of Shenzhen (No. JCYJ20170307104838077), the Medical Research Foundation of Guangdong Province (No. B2018150), the National Natural Science Foundation of China (No.81472275) and the Natural Science Foundation of Guangdong Province, China (No.2014A030313542). They played an important role in research design, analyzing and interpreting data, and paper writing.

\section{Availability of data and materials}

All data generated or analyzed during this study are included in this published article.

\section{Ethics approval and consent to participate}

We confirm that none of the cell lines in the current study required ethics approval for their use. The human study was conducted in accordance with the Declaration of Helsinki (2013). The use of tissue specimens was based on an informed and voluntary principle, and was reviewed and approved by the Ethics Committee of Longgang District People's Hospital of Shenzhen. Written informed consent to participate in this study has been obtained from all participants.

\section{Consent for publication}

Not applicable (N/A).

\section{Competing interests}

The authors declare that they have no competing interests.

\section{Author details}

'Department of Hematology, Longgang District People's Hospital of Shenzhen, Shenzhen 518172, Guangdong, China. ${ }^{2}$ Department of
Hematology, The First Affiliated Hospital, Sun Yat-Sen University, Guangzhou 510080, Guangdong, China. ${ }^{3}$ Department of Pathology, School of Basic Medicine, Guangdong Medical University, Dongguan 523808, Guangdong, China. ${ }^{4}$ Department of Hematology, The Seventh Affiliated Hospital, Sun Yat-Sen University, Shenzhen 518107, China. ${ }^{5}$ Department of Hematological Oncology, Shenzhen University General Hospital, Shenzhen 518055, China.

Received: 1 March 2019 Accepted: 16 December 2019

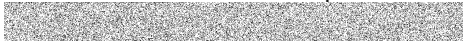

\section{References}

1. Walker BA, Mavrommatis K, Wardell CP, Ashby TC, Bauer M, Davies FE, et al. Identification of novel mutational drivers reveals oncogene dependencies in multiple myeloma. Blood. 2018;132(6):587-97.

2. Starheim KK, Holien T, Misund K, Johansson I, Baranowska KA, Sponaas AM, Hella H, Buene G, Waage A, Sundan A, Bjørkøy G. Intracellular glutathione determines bortezomib cytotoxicity in multiple myeloma cells. Blood Cancer J. 2016 Jul 15;6(7):e446. https://doi.org/10.1038/bcj.2016.56.

3. Dingli D, Sikander A, Leif Bergsagel P, Buadi FK, Dispenzieri A, Fonseca R, et al. Therapy for relapsed multiple myeloma: guidelines from the Mayo stratification for myeloma and risk-adapted therapy. Mayo Clin Proc. 2017; 92(4):578-98.

4. Dankbar B, Padró T, Leo R, Feldmann B, Kropff M, Mesters RM, et al. Vascular endothelial growth factor and interleukin-6 in paracrine tumor-stromal cell interactions in multiple myeloma. Blood. 2000;95(8):2630-6.

5. Chen H, Campbell RA, Chang Y, Li M, Wang CS, Li J, et al. Pleiotrophin produced by multiple myeloma induces transdifferentiation of monocytes into vascular endothelial cells: a novel mechanism of tumor-induced vasculogenesis. Blood. 2009;113(9):1992-2002.

6. Tai YT, Li XF, Breitkreutz I, Song W, Neri P, Catley L, et al. Role of B-cellactivating factor in adhesion and growth of human multiple myeloma cells in the bone marrow microenvironment. Cancer Res. 2006;66(13):6675-82.

7. Kukreja A, Hutchinson A, Dhodapkar K, Mazumder A, Vesole D, Angitapalli R, et al. Enhancement of clonogenicity of human multiple myeloma by dendritic cells. J Exp Med. 2006;203(8):1859-65.

8. Sandel MH, Dadabayev AR, Menon AG, Morreau H, Melief CJ, Offringa R, et al. Prognostic value of tumor-infiltrating dendritic cells in colorectal cancer: role of maturation status and intratumoral localization. Clin Cancer Res. 2005;11(7):2576-82.

9. Bahlis NJ, King AM, Kolonias D, Carlson LM, Liu HY, Hussein MA, et al. CD28mediated regulation of multiple myeloma cell proliferation and survival. Blood. 2007;109(11):5002-10

10. Josselin N, Libouban $H$, Dib M, lfrah N, Legrand $E$, Baslé MF, et al. Quantification of dendritic cells and osteoclasts in the bone marrow of patients with monoclonal gammopathy. Pathol Oncol Res. 2009;15(1):65-72.

11. Hong S, Qian J, Yang J, Li H, Kwak LW, Yi Q. Roles of idiotype-specific t cells in myeloma cell growth and survival: Th1 and CTL cells are tumoricidal while Th2 cells promote tumor growth. Cancer Res. 2008;68(20):8456-64.

12. Zheng C, Huang D, Liu L, Wu R, Bergenbrant Glas S, Osterborg A, et al. Interleukin-10 gene promoter polymorphisms in multiple myeloma. Int J Cancer. 2001;95(3):184-8.

13. Nagai H, Hara I, Horikawa T, Oka M, Kamidono S, Ichihashi M. Elimination of CD4(+) T cells enhances anti-tumor effect of locally secreted interleukin-12 on B16 mouse melanoma and induces vitiligo-like coat color alteration. J Invest Dermatol. 2000;115:1059-64.

14. Yi Q, Osterborg A, Bergenbrant S, Mellstedt H, Holm G, Lefvert AK. Idiotypereactive T-cell subsets and tumor load in monoclonal gammopathies. Blood. 1995;86:3043-9.

15. Yi Q, Osterborg A. Idiotype-specific T cells in multiple myeloma: targets for an immunotherapeutic intervention. Med Oncol. 1996;13:1-7.

16. Ostad M, Andersson M, Gruber A, Sundblad A. Expansion of immunoglobulin autoreactive T-helper cells in multiple myeloma. Blood. 2008;111:2725-32

17. Tian F, li J, Li Y, Luo S. Enhancement of myeloma development mediated though myeloma cell-Th2 cell interactions after microbial antigen presentation by myeloma cells and DCs. Blood Cancer J. 2012;2:e74. https:// doi.org/10.1038/bcj.2012.19.

18. Di Lullo G, Marcatti M, Heltai S, Brunetto E, Tresoldi C, Bondanza A, et al. Th22 cells increase in poor prognosis multiple myeloma and promote tumor cell growth and survival. Oncoimmunology. 2015:4(5):e1005460 eCollection 2015. 
19. Moss SF, Blaser MJ. Mechanisms of disease: inflammation and the origins ofcancer. Nat Clin Pract Oncol. 2005;2:90-7.

20. Mantovani A, Allavena P, Sica A, Balkwill F. Cancer-related inflammation. Nature. 2008:454:436-44

21. DeClerck YA, Mercurio AM, Stack MS, Chapman HA, Zutter MM, Muschel RJ, et al. Proteases, extracellular matrix, and cancer: a workshop of the path B study section. Am J Pathol. 2004;164:1131-9.

22. Stritzker J, Weibel S, Hill PJ, Oelschlaeger TA, Goebel W, Szalay AA. Tumorspecific colonization, tissue distribution, and gene induction by probiotic Escherichia coli Nissle 1970 inlive mice. Int J Med Microbiol. 2007;297(3):151-62.

23. Piñero-Lambea C, Bodelón G, Fernández-Periáñez R, Cuesta AM, ÁlvarezVallina L, Fernández LÁ. Programming controlled adhesion of E. coli to target surfaces, cells, and tumors with synthetic adhesins. ACS Synth Biol. 2015;4(4):463-73. https://doi.org/10.1021/sb500252a Epub 2014 Jul 29.

24. Giannakis M, Chen SL, Karam SM, Engstrand L, Gordon Jl. Helicobacter pylori evolution during progression from chronic atrophic gastritis to gastric cancer and its impact on gastric stem cells. Proc Natl Acad Sci U S A. 2008; 105:4358-63.

25. Yi Q, Dabadghao S, Osterborg A, Bergenbrant S, Holm G. Myeloma bone marrow plasma cells: evidence for their capacity as antigen-presenting cells. Blood. 1997;90:1960-7.

26. Moss Steven F, Martin J. Blaser. Mechanisms of disease: inflammation and the origins of cancer. Nat Clin Pract Oncol. 2005;2:90-7.

27. Chang JT, Palanivel VR, Kinjyo I, Schambach F, Intlekofer AM, Banerjee A, Longworth SA, et al. Asymmetric T lymphocyte division in the initiation of adaptive immune responses. Science. 2007;315:1687-91.

28. Sharma A, Khan R, Joshi S, Kumar L, Sharma M. Dysregulation in Thelper 1/ Thelper 2 cytokine ratios in patients with multiple myeloma. Leuk Lymphoma. 2010;51(5):920-7. https://doi.org/10.3109/10428191003699563.

29. Feng $P$, Yan R, Dai X, Xie X, Wen H, Yang S. The alteration and clinical significance of Th1/Th2/Th17/Treg cells in patients with multiple myeloma. Inflammation. 2015 Apr;38(2):705-9. https://doi.org/10.1007/s10753-0149980-4.

30. Cosmi L, Annunziato F, Galli MIG, Maggi RME, Nagata K, Romagnani S. CRTH2 is the most reliable marker for the detection of circulating human type 2 Th and type 2 T cytotoxic cells in health and disease. Eur J Immunol. 2000;30:2972-9.

31. Randolph DA, Huang G, Carruthers CJ, Bromley LE, Chaplin DD. The role of CCR7 in TH1 and TH2 cell localization and delivery of B cell help in vivo. Science. 1999;286:2159-62

32. MacLennan IC, Toellner KM, Cunningham AF, Serre K, Sze DM, Zuniga E, et al. Extrafollicular antibody responses. Immunol Rev. 2003;194:8-18.

33. Takazawa Y, Kiniwa Y, Ogawa E, Uchiyama A, Ashida A, Uhara H, et al. Tolllike receptor 4 signaling promotes the migration of human melanoma cells. Tohoku J Exp Med. 2014;234(1):57-65.

\section{Publisher's Note}

Springer Nature remains neutral with regard to jurisdictional claims in published maps and institutional affiliations.

Ready to submit your research? Choose BMC and benefit from:

- fast, convenient online submission

- thorough peer review by experienced researchers in your field

- rapid publication on acceptance

- support for research data, including large and complex data types

- gold Open Access which fosters wider collaboration and increased citations

- maximum visibility for your research: over $100 \mathrm{M}$ website views per year

At $\mathrm{BMC}$, research is always in progress.

Learn more biomedcentral.com/submissions 